\title{
Rede Social de Apoio de Mães com Deficiência Intelectual
}

\author{
Social Support Networks for Mothers with Intellectual Disability
}

\author{
Glauce Munira Silveira Araújo* \& Ana Lúcia Rossito Aiello \\ Universidade Federal de São Carlos, São Carlos, São Paulo, Brasil
}

\begin{abstract}
Resumo
Este estudo caracterizou a rede de apoio de mães com deficiência intelectual e analisou a opinião das pessoas que lhes fornecem apoio. Participaram do estudo cinco mães com deficiência intelectual e oito fontes de apoio. Foram realizadas entrevistas de levantamento de dados, entrevista com as mães sobre apoio social e entrevista com as fontes de apoio acerca do apoio fornecido. Os resultados demonstraram restrita rede social, constituída majoritariamente por familiares e por apoio prático, além de histórias de vida difíceis. Tais dados apontam a necessidade de serviços que favoreçam o aumento da rede social dessas mães e o tipo de apoio, e a importância de futuros estudos que investiguem os aspectos envolvidos no isolamento social e na maternidade dessas mulheres.

Palavras-chave: Rede social de apoio, mães com deficiência mental, Educação Especial.
\end{abstract}

\begin{abstract}
This study characterized the support network offered to mothers with intellectual disability and analyzed the views of people who provide them support. Five mothers with intellectual disability and eight sources of support participated in the study. An interview about social support was conducted with the mothers and another interview about the support provided was conducted with the sources of support for data collection. The results showed limited social network, mainly consisted by family members and practical support, and difficult life histories as well. These data indicate the need for services that increase the social network of those mothers and the types of support, and that favor the importance of future studies to investigate the issues involved in social isolation and maternity of such women.

Keywords: Support network, mothers with intellectual disabilities, Special Education.
\end{abstract}

A maternidade e paternidade de pessoas com deficiência intelectual ainda pode ser alvo de preconceitos, controvérsias e julgamentos de valor (Feldman, 1986; Llewellyn, Traustadóttir, McConnell, \& Sigurjónsdóttir, 2010), estando as famílias em que um ou ambos os pais possuem deficiência entre as minorias vulneráveis e isoladas da comunidade (Llewellyn \& McConnell, 1998). Sendo uma população minoritária, esses pais não têm suas necessidades em relação à educação, treinamento e apoio atendidas adequadamente pelos serviços sociais e de saúde (Aiello \& Buonadio, 2003; Booth, 2003).

Além disso, são vistos como incapazes de criar seus filhos, fornecendo-lhes cuidados inadequados, abusando deles, maltratando-os e/ou negligenciando-os. É importante se considerar, no entanto, fatores de risco aos quais essas famílias muitas vezes estão expostas, como pobreza ou baixo nível socioeconômico, isolamento social, grande

* Endereço para correspondência: Avenida Miguel Damha, 1000, Unidade 155, Parque Tecnológico Damha de São Carlos, São Carlos, SP, Brasil 13565-902. E-mail: glaupsico@yahoo.com.br

Esta pesquisa contou com auxílio financeiro da Fundação de Amparo à Pesquisa do Estado de São Paulo (FAPESP). número de filhos e falta de serviços apropriados que as apoiem (Llewellyn, 1993, 1994; Llewellyn \& McConnell, 1998; Postalli, Munuera, \& Aiello, 2011; Whitman, Graves, \& Accardo, 1989; Willems, de Vries, Isarin, \& Reinders, 2007); falta de apoios formais e informais, e ausência de modelos adequados de papéis parentais (Holburn, Perkins, \& Vietze, 2001; Sheerin, 1998; Whitman et al., 1989). Tais fatores, associados ao déficit cognitivo e de comportamento adaptativo dessas pessoas, podem ter efeitos significativos no exercício de sua maternidade/ paternidade (Gallagher, 2001; Whitman et al., 1989) ao se configurarem como restrições sociais que propiciam as dificuldades que esses pais podem ter (Llewellyn \& McConnell, 1998).

Diante de todas essas dificuldades, a presença de uma rede social de apoio é de extrema importância para que garantam o seu direito à maternidade/paternidade, e a exerçam com o mínimo de adequação, visto que a presença de um apoio substancial pode ajudar no desenvolvimento de habilidades parentais, na criação dos filhos e na manutenção dos mesmos sob sua custódia (Aiello \& Buonadio, 2003; Tarleton \& Ward, 2007; Traustadóttir \& Sigurjónsdóttir, 2008; Willems et al., 2007). 
Cabe ressaltar que a definição de apoio social não é consensual, havendo um amplo campo de discussão na literatura tratando de tal questão. Na presente pesquisa, a definição adotada será a de Thompson et al. (2002), os quais colocam o apoio social como recursos e estratégias de assistência que atendem aos interesses e promovem o bem-estar do indivíduo, destacando a independência pessoal e a produtividade, aumentando a participação em uma sociedade interdependente, a integração comunitária, e/ou a melhoria da qualidade de vida. Segundo Llewellyn e McConnell (2002) as ações mais comuns de apoio incluem apoio prático ou ajuda material (por exemplo, ajuda financeira ou para cuidado do filho, transporte); informações, conselhos ou sugestões (para soluções de problemas, sobre desenvolvimento e saúde da criança); apoio emocional (ouvir com empatia, consolar em momentos difíceis, encorajar bons papéis parentais) e companhia ou interação social positiva (coparticipação em atividades de lazer e recreação).

O papel primordial das redes de apoio refere-se à proteção contra eventos estressantes, principalmente aqueles advindos de transições vitais, e ao alívio de estresse físico e mental (Cassel, 1976; Dessen \& Braz, 2000). Em relação aos indivíduos com deficiência intelectual, além de fornecerem tais benefícios, as redes de apoio podem ser responsáveis pela melhoria da qualidade de vida e pela manutenção da saúde física e mental e do bem-estar (Booth \& Booth, 1994; Kroese, Hussein, Clifford, \& Ahmed, 2002; Llewellyn \& McConnell, 2002; McConnell, Dalziel, Llewellyn, Laidlaw, \& Hindmarsh, 2009). Podem também estar relacionadas a estilos positivos de interação entre a mãe deficiente e seus filhos (Feldman, Varghese, Ramsay, \& Rajska, 2002), e à compensação de limitadas habilidades parentais (Llewellyn \& McConnell, 1998).

Alguns estudos sobre as redes sociais de apoio dessas pessoas, em especial das mães, têm demonstrado a tendência ao isolamento social a que estão expostas. Llewellyn e McConnell (2002) investigaram a opinião de 70 mães com dificuldades de aprendizagem sobre o apoio social recebido por elas. Os dados mostraram que cerca de $47 \%$ das fontes de apoio eram familiares; $26,4 \%$ eram profissionais; $21,6 \%$ eram amigos; e $5 \%$ vizinhos. Resultados semelhantes foram encontrados por Guinea (2001) em seu estudo sobre a satisfação de pais com deficiência intelectual com o apoio que recebem, e as discrepâncias entre o tipo de apoio desejado e o recebido. Verificou-se que os pais entrevistados possuíam pequenas redes (média de 4,5 membros), sendo $52,7 \%$ de familiares, $30,5 \%$ de profissionais, e 16,6\% de amigos. A presença de vizinhos não foi relatada.

Outro estudo realizado nesse sentido foi o de Kroese et al. (2002), no qual características das redes de apoio de 15 mães com deficiência intelectual foram investigadas. Os resultados mostraram que essas mães pareciam ter uma rede social de 6,8 pessoas em média, caindo para 5,4 se forem considerados apenas os laços sociais referidos pelas mães como sendo úteis. $O$ aspecto mais útil do apoio social relatado pelas mães foi "ajuda na dificuldade", ou seja, apoio durante crises. Ajuda para cuidar das crianças e disponibilidade (ouvir, estar presente e perguntar se a mãe quer ajuda) também foram vistos como aspectos importantes do apoio social. Além disso, verificou-se que apenas $28,43 \%$ dos laços sociais referiam-se a pessoas que não eram da família, indicando a existência de poucos amigos, vizinhos e laços formais. Observou-se ainda que o bem-estar psicológico estava positivamente correlacionado com o tamanho da rede, ressaltando a importância de uma rede de apoio ampla na vida dessas pessoas.

Estudo realizado por Aunos, Feldman e Goupil (2008) com 32 mães com deficiência intelectual também forneceu dados semelhantes sobre o tamanho e a composição da rede de apoio dessa população. As mães tiveram, em média, 7,41 pessoas em sua rede social de apoio, composta predominantemente por membros da família, em especial mães, sogras e parceiros. O segundo maior grupo foi de profissionais, seguidos por amigos e vizinhos, e então colegas de trabalho. Além disso, apontou a importância da participação de outros membros da família e de uma figura parental para apoiar a mãe em sua dificuldade de prover ambiente adequado a seus filhos.

Como pode ser observado, a literatura da área (Aunos et al., 2008; Guinea, 2001; Kroese et al., 2002; Llewellyn \& McConnell, 2002) aponta para a existência de uma pequena rede social em comparação à média encontrada em pais sem deficiência intelectual - em média 13 laços sociais (Levitt et al., 1986, como citado em Kroese et al., 2002). Além disso, indica pouca variedade na composição da rede dessas mães. Os dados anteriormente apresentados confirmam ainda mais a questão do isolamento social presente na vida de pais com deficiência, sendo preocupante $\mathrm{e}$ merecendo atenção especial, particularmente na elaboração e desenvolvimento de programas destinados a eles.

Booth e Booth (2002) realizaram um estudo pioneiro ao considerar a importância central do homem na maternidade de 55 mulheres com deficiência intelectual. Tal estudo teve como objetivo examinar criticamente a hipótese de que o uso, abuso e abandono de mães com deficiência intelectual por seus parceiros é algo comum em suas vidas. Os autores demonstraram que alguns parceiros tanto abusavam quanto apoiavam as mulheres em relação aos cuidados com os filhos, e que metade dos parceiros que não apoiavam suas esposas abusavam delas. Foram verificados casos de abuso e violência em $21,8 \%$ dos relacionamentos, os quais eram curtos e instáveis, sendo os abusadores homens sem deficiência, em sua maioria. O comportamento desses homens caracterizava-se por abuso físico e sexual e por comportamento violento. Tais resultados fornecem suporte para a concepção de que a mulher com deficiência corre o risco de estar envolvida com homens problemáticos.

Outro estudo que considera a questão do abuso cometido contra essas mães é o de Ehlers-Flint (2002), que entrevistou 20 mães com déficits cognitivos, na tentativa de identificar a extensão das suas experiências de maternidade e explorar a relação entre vulnerabilidade e apoio social. 
Em geral, os resultados mostraram que embora apoiassem de alguma forma, membros da família e parentes foram vistos como maior fonte de interferência em comparação a membros da comunidade e terapeutas, por exemplo. Demonstraram também haver escassez de relacionamentos com pares e a percepção de que relacionamento com pessoas da comunidade é menos estressante. Dificuldades com o isolamento social e o desejo de expandir as redes sociais foram expressos pelas mães. Além disso, o estudo mostrou que $50 \%$ das mulheres entrevistadas haviam sido abusadas e/ou negligenciadas, sendo os perpetradores, em sua maioria, membros da família ou homens com quem tiveram um relacionamento.

As pesquisas existentes no Brasil sobre mães com deficiência intelectual são escassas, sendo a sua ampliação um desafio para pesquisadores (Aiello \& Buonadio, 2003; Postalli et al., 2011). Além disso, pesquisas sobre as redes sociais de apoio dessas mães e sobre o papel de quem apoia, especialmente do parceiro, parecem ser inexistentes no país.

Pesquisas no sentido de suprir essas lacunas podem abrir caminhos para futuros estudos visando intervenções para amenizar efeitos de isolamento social e violência e, consequentemente, chamar a atenção das políticas públicas para a importância de considerar o indivíduo e sua rede de apoio ao se desenvolver programas destinados a essa população.

Dessa forma, o presente estudo teve como objetivos: (a) caracterizar a rede social de apoio de mães com deficiência intelectual e (b) analisar a opinião de pessoas que fornecem apoio para essas mães sobre a ajuda que fornecem e sobre suas necessidades, dificuldades e limitações para apoiar a família.

\section{Método}

\section{Participantes}

Participaram do estudo cinco mães com deficiência intelectual, todas ex-alunas de uma Associação de Pais e Amigos do Excepcional (APAE), e oito pessoas (denominadas fontes de apoio) indicadas pelas mães como lhes fornecendo apoio, totalizando treze participantes.

A idade média das mães era de 36 anos, estando sua faixa etária entre 28 e 42 anos. Todas as mães frequentaram a APAE por períodos que variaram entre 2 e 10 anos, sendo que uma mãe não completou o Ensino Fundamental, e as outras duas o finalizaram. Três participantes eram casadas, uma divorciada e uma nunca se casou. A idade média dos parceiros era de 37 anos, variando de 33 a 40 anos. Dois deles eram pais biológicos das crianças. Quanto à escolaridade, dois parceiros não completaram o Ensino Fundamental e um completou o Ensino Médio. O número de filhos variou entre 1 e 4 ; e a idade deles encontrava-se entre 4 e 19 anos. Três crianças tinham deficiência intelectual, uma apresentava dificuldades de aprendizagem, e uma tinha deficiência auditiva, sendo quatro delas alunas da APAE. Quanto à situação socioeconômica das famílias, verificou-se que uma família pertencia à classe socioeconômica $\mathrm{C}$ e as outras quatro famílias à classe $\mathrm{D}$ (Associação Brasileira de Empresas de Pesquisas [ABEP], 2007). A renda mensal variou de $\mathrm{R} \$ 310,00$ a $\mathrm{R} \$ 1030,00$. Duas famílias moravam em casas próprias, duas em casas cedidas, e uma em casa alugada.

Em relação às fontes de apoio, a idade média era de 43 anos, variando entre 25 e 73 anos. Quanto ao nível de escolaridade houve grande variedade - analfabetismo $(n=1)$, Ensino Fundamental incompleto $(n=2)$, Ensino Médio incompleto $(n=1)$, e Ensino Superior completo $(n=1)$. Das oito fontes de apoio, cinco eram casadas, duas eram viúvas e uma era solteira. Duas dessas pessoas não possuíam filhos, e as outras seis tinham de um a quatro filhos. A família de uma das fontes de apoio pertencia à classe socioeconômica $\mathrm{B} 1$, cinco à classe $\mathrm{C}$ e duas à classe D (ABEP, 2007). A renda mensal de cada família variou de $\mathrm{R} \$ 600,00$ a $\mathrm{R} \$ 3500,00$. Dentre as famílias, duas moravam em casa alugada, cinco em casa própria, e uma em barraco cedido.

\section{Procedimento}

A presente pesquisa foi aprovada pelo Comitê de Ética em Pesquisa para Experimentos em Seres Humanos da Universidade Federal de São Carlos (UFSCar), e os participantes assinaram duas vias do Termo de Consentimento Livre e Esclarecido (TCLE). O TCLE para as mães diferiam do TCLE das fontes de apoio na linguagem utilizada e no conteúdo do mesmo, sendo o termo das mães escrito com mais detalhes e em linguagem mais simples e informal.

Primeiramente foi realizada a seleção das mães participantes do estudo, a qual ocorreu através da indicação de profissionais da APAE de alunos cujas mães já frequentaram a instituição e, portanto, eram mães com diagnóstico de deficiência intelectual. Cabe ressaltar que a seleção de ex-alunas de instituição de ensino para pessoas com deficiência foi adotada por ser um recurso que viabiliza a busca e a localização das participantes, uma vez que no Brasil não há serviços destinados a tais mães. Entretanto, acesso a informações sobre o nível de deficiência e grau de comprometimento dessas mulheres não foi possível.

Após contato prévio com as mães indicadas e concordância em participarem da pesquisa, deu-se início à coleta de dados, realizada pela pesquisadora na residência de cada participante. Os seguintes instrumentos foram aplicados às mães participantes:

Entrevista Inicial com Mães. Entrevista baseada em Williams e Aiello (2001), composta por 9 campos, que visa caracterizar as famílias das mães participantes em termos de identificação (por exemplo, nome, idade, escolaridade, etc.) e de aspectos sociodemográficos da família (por exemplo, número de filhos, renda, habitação, etc.).

Critério de Classificação Econômica Brasil. Questionário de avaliação socioeconômica desenvolvido pela 
Araújo, G. M. S. \& Aiello, A. L. R. (2013). Rede Social de Apoio de Mães com Deficiência Intelectual.

ABEP (2007), o qual mede a capacidade de consumo e o grau de escolaridade do chefe da família, classificando a família em uma dentre sete classes econômicas (A1, A2, B1, B2, C, D, E).

Entrevista sobre Apoio Social para Mães com Deficiência Intelectual. Instrumento traduzido pelas pesquisadoras a partir de instrumento utilizado por Llewellyn e McConnell (1999), construído especialmente para pessoas com deficiência mental, com cartões de respostas coloridos e representações gráficas para ilustrar as diferentes dimensões de apoio e facilitar a compreensão das respondentes. Objetiva a caracterização do apoio social recebido pelas mães e a identificação de fontes de apoio, e é dividida em quatro partes, cada uma composta por uma questão: (a) verifica o tamanho e a composição da rede de apoio da mãe; (b) identifica as fontes de cada tipo de apoio (emocional, prático, informativo, companheirismo) e computa a variedade da rede, definida como o número de diferentes tipos de apoio disponibilizados por cada fonte (Llewellyn \& McConnel, 2002); (c) indicação pelas mães da proximidade/intimidade de cada uma das pessoas citadas por ela como fontes de apoio; e (d) explora características da rede como frequência e tipo de contato com cada fonte, duração do relacionamento, proximidade geográfica, dentre outras.

A partir das respostas a essa entrevista, foram selecionadas duas pessoas cujo apoio fornecido às mães é útil, ou seja, aquelas pessoas citadas como fornecendo variedade de apoio, como estando próximas à mãe (física e emocionalmente), e cujo contato seja constante (variando entre "todo dia" e "mensalmente"). Identificadas estas pessoas, as mesmas foram contactadas para que participassem do estudo. Das dez pessoas identificadas, duas não aceitaram participar, totalizando oito fontes de apoio. Com as fontes de apoio foram utilizados: Entrevista Inicial com Mães e Critério de Classificação Econômica Brasil aplicados com as mães; e:

Entrevista sobre Apoio Social para Fontes de Apoio. Roteiro de entrevista semiestruturada composto por trinta e três questões, o qual foi construído pelas autoras do presente estudo com o objetivo de explorar a opinião de fontes de apoio das mães. Os temas abordados foram os tipos de apoio oferecidos; frequência do contato entre a mãe e a fonte; duração do relacionamento entre elas, necessidades de recursos para fornecer apoio, sentimentos da pessoa ao fornecer apoio, como vê a experiência de apoiar uma pessoa com deficiência mental, implicações disso em sua vida, avaliação do próprio apoio e do apoio de terceiros.

\section{Resultados}

\section{Qual a História de Vida dessas Mães?}

Os dados obtidos por meio das entrevistas realizadas com as mães e de comentários feitos por elas permitiram uma descrição do histórico de vida de cada uma e um re- trato de suas condições de vida. De forma geral, tais dados parecem indicar uma história de vida difícil, marcada por singularidades, sendo as adversidades e os aspectos negativos uma constante em suas vidas. Dentre eles podemos citar preconceito, exclusão e discriminação; fatores de risco (baixo nível socioeconômico, falta de apoios formais e informais orientados e planejados para assistir essas mães em diferentes necessidades, ausência de modelos maternos adequados, vulnerabilidade a abuso e violência, presença de vários parceiros); e fatores estressantes (medo de remoção e perda da guarda dos filhos, cuidados pré-natais pobres, ausência de parceiro em alguns casos).

Embora dificuldades sejam predominantes na vida de muitas dessas mulheres, aspectos positivos estão presentes em alguns casos. Dentre eles podemos citar a presença de maridos que parecem apoiar, não abusar ou agredir a esposa; habilidades adaptativas que podem ter ajudado na criação dos filhos, na manutenção de um relacionamento duradouro e no exercício de uma profissão; a presença de pessoas próximas, ainda que somente familiares, fornecendo apoio e ajuda.

O que as Mães Dizem sobre o Apoio Social Recebido?

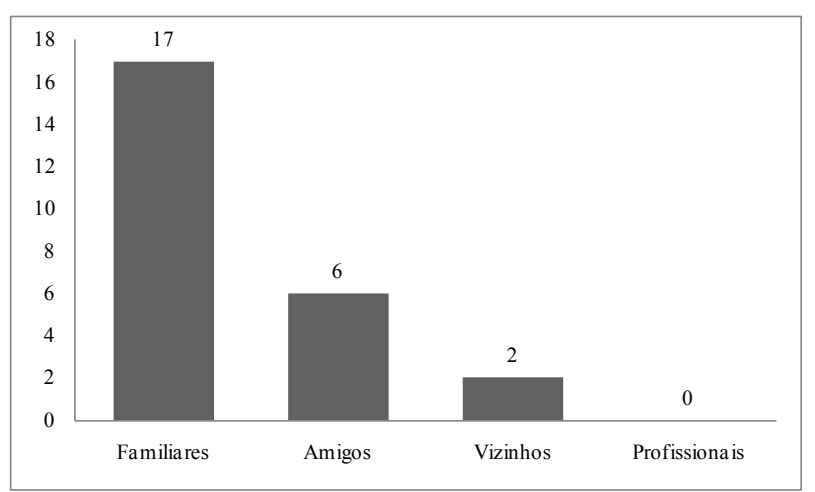

Figura 1. Fontes de apoio das mães de acordo com o tipo de relacionamento.

A Figura 1 representa o tamanho da rede de apoio das mães e sua composição, de acordo com o tipo de relação entre as mães e suas fontes de apoio. Os resultados apontam 25 fontes de apoio no total, ou seja, uma média de cinco fontes por mãe, sendo 17 membros da família (68\%), 6 amigos (24\%), 2 vizinhos (8\%) e nenhum profissional. Tais dados indicam que a rede de apoio de mães com deficiência intelectual tende a ser composta majoritariamente por familiares, enquanto o número de amigos é pequeno, o de vizinhos é mínimo, e o de profissionais é nulo. Além disso, demonstram uma tendência geral a uma rede de apoio escassa, indicando falta de apoio formal e informal e isolamento social dessa população.

Quanto ao tipo de apoio recebido pelas mães, a Figura 2 indica que os tipos de apoio recebidos em maior e menor quantidade eram, respectivamente, $\mathrm{o}$ apoio prático e o apoio emocional. Alguns exemplos de apoio prático 
citados pelas mães foram ajuda com recursos financeiros e materiais e ajuda nas atividades domésticas e com as crianças. Já o apoio emocional, embora fosse limitado a conversas quando as mães estavam com algum problema e ajuda na resolução dos mesmos, foi considerado útil e importante. Sobre a ajuda com informações ou conselhos, foram citados o esclarecimento de dúvidas, informações sobre algo desconhecido, e conselhos em geral. Por fim, quanto à companhia, as mães que recebiam tal apoio relataram tomar café com algumas das fontes de apoio e passear às vezes. Foi possível observar que atividades de lazer e descanso não eram frequentes.

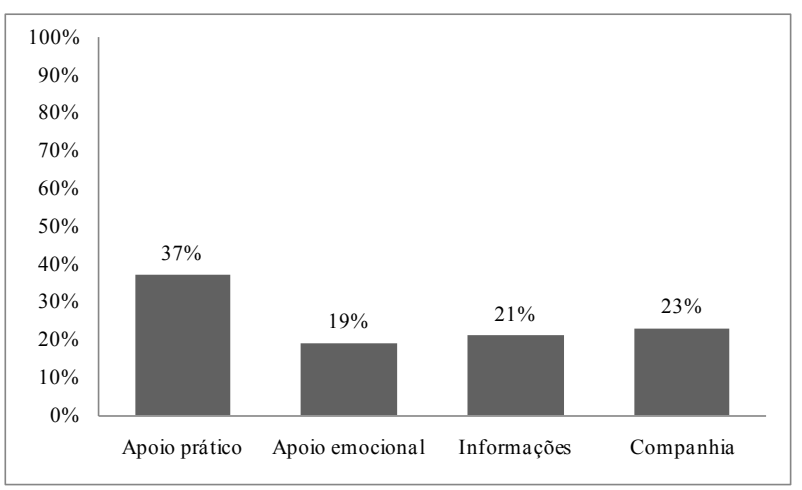

Figura 2. Porcentagem de cada tipo de apoio recebido pelas mães.

\section{O que as Fontes de Apoio Dizem sobre o Apoio que Fornecem?}

A Tabela 1 apresenta a descrição do apoio fornecido pelas fontes de apoio participantes. Como pode ser observado, o apoio prático fornecido para grande parte das mães constituiu-se de ajuda financeira (empréstimo de dinheiro), doação de mantimentos para a família e de materiais, roupas e calçados para as crianças, assim como apontado pelas mães. $\mathrm{O}$ apoio emocional, o qual não havia sido relatado por algumas mães como oferecido pelas fontes entrevistadas, consistiu-se em conversas a fim de ajudar na resolução de problemas ou de animar a mãe. Quanto à ajuda com informações ou conselhos, foram indicados conselhos em geral e sobre as crianças, e informações demandadas pelas mães, concordando com os relatos destas. Por fim, assim como indicado pelas mães, companhia resumiu-se em "tomar cafe" ou ir a algum lugar quando solicitado por elas.

De acordo com os dados obtidos, pode-se verificar a prevalência do fornecimento de apoio prático, e reduzido fornecimento de companhia, em concordância com os relatos das próprias mães. De forma geral, quando se compara os relatos das fontes de apoio com o das mães, nota-se maior quantidade e variedade de apoio oferecido, a partir da percepção daquelas.

A análise das respostas referentes à opinião sobre o apoio que fornecem às mães, sua satisfação em ajudar, dificuldades, necessidades e limitações, indica alguns aspectos comuns entre elas. De forma geral, as fontes de apoio sentiram-se satisfeitas em ajudar, e o apoio fornecido foi percebido por elas como útil e importante para a vida da mãe. Entretanto, a Ft 2 de M4 considerou o apoio que fornece como razoável, pois gostaria de oferecer mais. Esta também foi a opinião da Ft1 de M5, embora tenha classificado seu apoio como útil. As duas fontes citadas foram as únicas a relatarem necessidade de algo para apoiar as mães de uma melhor forma, referindo-se a recursos financeiros. Quanto às dificuldades e limitações para fornecer apoio, as respostas variaram, sendo que nenhuma das fontes de apoio de M1 mencionou esses aspectos. Destacam-se as fontes de M2, cujos relatos indicam comprometimento do próprio orçamento, pois deixam de pagar suas contas ou de comprar coisas para si, e sobrecarga pelo montante de ajuda que M2 demanda. Tais fontes afirmam que não vale a pena o esforço para ajudar, pois consideram que a mãe não reconhece ou valoriza a ajuda.

Por fim, os dados obtidos demonstram ainda que as fontes de apoio apresentavam preocupação com a situação de vida da família, carinho e consideração por tais pessoas, e não se sentiam obrigados a ajudar, o que pode ter influência positiva sobre o apoio que oferecem, tornando-se um fator de proteção para as mães.

\section{Discussão}

Os resultados do presente estudo indicam que as mães com deficiência intelectual entrevistadas possuem uma pequena rede social de apoio - em média cinco pessoas, variando de 2 a 8 - em comparação à média encontrada em pais sem deficiência intelectual -13 pessoas aproximadamente (Levitt et al., 1986, citado por Kroese et al., 2002), indicando tendência ao isolamento social. Pequena rede de apoio também foi encontrada em estudos anteriores (Aunos et al., 2008; Guinea, 2001; Kroese et al., 2002; Llewellyn \& McConnell, 2002). No que diz respeito a quem fornece apoio para as mães, os resultados obtidos concordam com a literatura da área, sendo o apoio advindo majoritariamente de membros da família, com rara ajuda de amigos e vizinhos (Aunos et al., 2008; Guinea, 2001; Kroese et al., 2002; Llewellyn, 1995; Llewellyn \& McConnell, 2002; Postalli et al., 2011; Traustadóttir \& Sigurjónsdóttir, 2008). Desnecessário dizer que as pessoas que oferecem apoio não são pagas por essa ajuda, apesar de serem envolvidas e fundamentais para mães com deficiência intelectual. Elas podem mobilizar outros apoios, favorecendo as mães com deficiência e o desenvolvimento infantil, além de ajudá-las a obter serviços e apoios na comunidade, diminuir riscos de saúde e segurança e enriquecer a vida diária das mães.

Entretanto, familiares como principal fonte de apoio das mães pode indicar uma falta de alternativas às quais elas poderiam recorrer para receber ajuda e apoio necessários. De acordo com Traustadóttir e Sigurjónsdóttir (2008), devido ao fato destas mães não receberem serviços de apoio formais, a única possibilidade para manterem os filhos sob sua custódia era receber assistência e proteção 
Araújo, G. M. S. \& Aiello, A. L. R. (2013). Rede Social de Apoio de Mães com Deficiência Intelectual.

Tabela 1

Apoio Fornecido pelas Principais Fontes de Apoio

\begin{tabular}{|c|c|c|c|}
\hline Mãe & Fonte & Tipo de apoio & Descrição do apoio \\
\hline M1 & Ft1 (amiga) & $\begin{array}{l}\text { Prático } \\
\text { Emocional } \\
\text { Informações/conselhos } \\
\text { Companhia }\end{array}$ & $\begin{array}{l}\text { Empréstimo de dinheiro, cestas básicas, roupas para as crianças } \\
\text { Nenhum } \\
\text { Conselhos sobre a educação das crianças } \\
\text { Café em sua casa }\end{array}$ \\
\hline & Ft2 (irmã 3) & $\begin{array}{l}\text { Prático } \\
\text { Emocional } \\
\text { Informações/conselhos } \\
\text { Companhia }\end{array}$ & $\begin{array}{l}\text { Compras de mantimentos } \\
\text { Conversa bastante e diz para M1 "ter paciência" } \\
\text { Conselhos sobre o que M1 deve ou não fazer } \\
\text { Nenhum }\end{array}$ \\
\hline M2 & Ft1 (irmã) & $\begin{array}{l}\text { Prático } \\
\text { Emocional } \\
\text { Informações/conselhos } \\
\text { Companhia }\end{array}$ & $\begin{array}{l}\text { Empréstimo de dinheiro, doação de móveis e cuidados com as crianças } \\
\text { Conversa sobre os problemas de M2 } \\
\text { Conselhos sobre as crianças } \\
\text { Nenhum }\end{array}$ \\
\hline & Ft2 (mãe) & $\begin{array}{l}\text { Prático } \\
\text { Emocional } \\
\text { Informações/conselhos } \\
\text { Companhia }\end{array}$ & $\begin{array}{l}\text { Empréstimo de dinheiro, cuidados com as crianças, compras de } \\
\text { mantimentos, roupas e calçados para as crianças } \\
\text { Conversa e diz para M2 "se animar" } \\
\text { Conselhos em geral } \\
\text { Nenhum }\end{array}$ \\
\hline M3 & Ft1 (irmã) & $\begin{array}{l}\text { Prático } \\
\text { Emocional } \\
\text { Informações/conselhos } \\
\text { Companhia }\end{array}$ & $\begin{array}{l}\text { Nenhum } \\
\text { Procura confortar M3, abraçando-a, dizendo que "não é por ai", dando } \\
\text { uma palavra amiga } \\
\text { Informações sobre receitas de comidas e sobre serviços para M3/ } \\
\text { conselhos em geral } \\
\text { Nenhum }\end{array}$ \\
\hline M4 & Ft1 (mãe) & $\begin{array}{l}\text { Emocional } \\
\text { Informações/conselhos } \\
\text { Companhia }\end{array}$ & $\begin{array}{l}\text { Permissão para que M4 compre coisas no seu nome, compras de } \\
\text { mantimentos, conversas com a neta e com pessoas com quem M4 } \\
\text { precisa conversar } \\
\text { Orientações sobre a vida de M4 } \\
\text { Conselhos sobre as crianças } \\
\text { Idas a algum lugar com M4 quando necessário }\end{array}$ \\
\hline & Ft2 (marido) & $\begin{array}{l}\text { Prático } \\
\text { Emocional } \\
\text { Informações/conselhos } \\
\text { Companhia }\end{array}$ & $\begin{array}{l}\text { Conserta coisas que quebram ou estragam na casa, atividades } \\
\text { domésticas quando necessário } \\
\text { Conversa e ajuda a resolver os problemas } \\
\text { Esclarecimento de dúvidas e conselhos sobre a filha de M4 } \\
\text { Conversas em casa à noite }\end{array}$ \\
\hline M5 & Ft1 (sobrinha) & $\begin{array}{l}\text { Prático } \\
\text { Emocional } \\
\text { Informações/conselhos } \\
\text { Companhia }\end{array}$ & $\begin{array}{l}\text { Comida pronta } 2 \text { vezes por semana, roupas, calçados e materiais } \\
\text { escolares para as crianças } \\
\text { Nenhum } \\
\text { Informações sobre algo que M5 pergunta } \\
\text { Nenhum }\end{array}$ \\
\hline
\end{tabular}

de membros da família, uma vez que essas mulheres ainda são consideradas mães incompetentes.

Conforme abordado por Willems et al. (2007) em seu estudo, a influência de um parceiro sem deficiência na vida de mães com deficiência intelectual, pode ser ambígua. Estendendo tal conclusão a outros familiares que apoiam essas mulheres, pode-se considerá-los como influência positiva e estruturante, ao reduzir a probabilidade dessas mães perderem a custódia dos filhos, por exemplo; mas também podem tornar as coisas mais difíceis, e as relações mantidas podem ser estremecidas, como é o caso de M2, em que suas fontes de apoio demonstram cansaço em ajudar e não serem valorizadas. De acordo com os autores isso acontece porque sistemas de apoio mal coordenados parecem minar ainda mais as habilidades parentais de pessoas que já são vulneráveis nesse aspecto. 
Apoio advindo em sua maioria de um mesmo grupo, ou seja, família, pode acabar sendo limitado e pouco variado. Portanto, é proeminente a necessidade de treinamentos de habilidades que permitam às mães ampliarem sua rede social e buscarem ajuda e apoio em outros lugares e de outras pessoas. Futuros estudos poderiam investigar, por exemplo, se o tamanho da rede de apoio das mães com deficiência intelectual depende e em que medida dos membros da família.

Em relação aos profissionais, na população estudada estes não foram identificados como estando presentes na rede de apoio das mães, o que difere dos resultados encontrados nos estudos citados anteriormente, todos internacionais (Aunos et al., 2008; Guinea, 2001; Llewellyn \& McConnell, 2002), em que a porcentagem de profissionais que fornece apoio para as mães é maior do que a porcentagem de amigos e vizinhos. Tal dado sugere a ausência de serviços públicos sociais e de saúde no Brasil destinados a essa população (Aiello \& Buonadio, 2003), enquanto o apoio de profissionais é frequente e comum no exterior.

Apoio recebido por algumas mães e que deve ser ressaltado é aquele fornecido por seus parceiros. As três mães casadas apontaram os maridos como lhes fornecendo algum tipo de ajuda e relataram sentir-se muito próximas a eles. Assim como em estudos realizados anteriormente (Booth \& Booth, 2002; Llewellyn, 1995), o tipo de apoio mais significativo para as mães pareceu ser o apoio prático e material (ajuda com atividades domésticas). Ajuda financeira, com os filhos, em atividades burocráticas, fornecimento de informações e companhia também foram relatados como apoios fornecidos pelos parceiros, porém em menor quantidade. Diante da presença constante desses homens na vida das mães com deficiência intelectual casadas, além de considerarem a opinião das próprias mães ao elaborar programas e intervenções para as mesmas, os serviços devem consultar os parceiros e envolvê-los, no intuito de permitir que os casais funcionem de uma forma mais colaborativa.

Enquanto as participantes casadas possuem um parceiro que as apoia de certa forma, aquelas que não o são ou que são divorciadas têm histórias de uso de álcool, abuso sexual e violência por parte de ex-parceiros, como já observado em estudos anteriores (Aiello \& Buonadio, 2003; Booth \& Booth, 2002; Buonadio, 2003; Ehlers-Flint, 2002; Gallagher, 2001; Holburn et al., 2001; Postalli et al., 2011; Sheerin, 1998; Whitman et al., 1989). Assim, os dados do presente estudo apoiam a concepção de que a mulher com deficiência corre o risco de estar envolvida com homens problemáticos (Booth \& Booth, 2002; Williams, 2003), além de não possuírem repertório de habilidades de autoproteção contra situações potencialmente abusivas do ponto de vista sexual (Barros, Williams, \& Brino, 2008).

Tais fatores devem ser considerados pelos serviços de atendimento a essa população, os quais devem também objetivar treinamentos de habilidades de autoproteção e empoderamento das mães com deficiência intelectual, a fim de diminuir sua vulnerabilidade ao abuso e violência, permitindo que elas saibam se defender e se proteger das ameaças à sua integridade física, moral e psicológica, além de terem recursos para buscar ajuda e segurança.

Embora haja algumas tendências no que diz respeito à rede social e ao apoio recebido pelas mães do presente estudo, nota-se certa heterogeneidade em relação a alguns aspectos, como é o caso do tamanho da rede de cada uma. Tais diferenças podem ser devido a características das próprias mães (nível da deficiência, autoestima, habilidades sociais, autoeficácia, empoderamento, etc.), ou ao contexto em que elas se encontram (condições socioeconômicas, número de filhos e idade dos mesmos, tamanho da família extensa, presença ou ausência de parceiros, empregabilidade, entre outros).

Dessa forma, futuros estudos deveriam investigar que aspectos podem contribuir para as diferenças entre as redes de apoio de mães com deficiência intelectual. A importância e utilidade do apoio fornecido pelos membros da rede social dessas mães, bem como seu impacto na vida de toda a família, também devem ser melhor e cuidadosamente investigados.

Cabe destacar que, embora algumas dessas mães tenham frequentado instituições para pessoas com deficiência, às vezes por longos períodos de tempo, poucas habilidades para lidar com situações cotidianas e de maternidade parecem ter sido ensinadas a elas (ou aprendidas por elas). Assim, nota-se a necessidade de um maior envolvimento e compromisso profissional, no sentido de mudar suas atitudes frente à maternidade de pessoas com deficiência intelectual, utilizando técnicas de aconselhamento e capacitação adequadas a tal população (Aiello \& Buonadio, 2003). Tais serviços devem ser baseados em conhecimentos buscados na literatura da área e, principalmente, na opinião das próprias pessoas institucionalizadas e seus familiares sobre suas reais necessidades.

Além da obtenção de importantes dados sobre a rede de apoio das mães com deficiência intelectual por meio de relatos próprios, outra contribuição do presente estudo refere-se à consideração da opinião das pessoas que fornecem apoio. Essa visão multifacetada permite-nos observar a rede de apoio dessas mulheres de forma mais ampla, em várias dimensões, facilitando o entendimento sobre o isolamento social, violência e demais adversidades que vivenciam, e sobre como se configura o apoio social presente em suas vidas.

De forma geral, os dados referentes aos tipos de apoio recebidos e oferecidos pelas mães e fontes de apoio, respectivamente, são complementares, embora os relatos das fontes apresentem maior quantidade e variedade de apoio - apoio emocional, por exemplo, que não havia sido relatado por algumas mães. Relatos de outras pessoas que compõem as redes de apoio dessas mães e que não foram entrevistadas podem ter essas mesmas características.

Diante disso, algumas possibilidades podem ser apontadas. Considerando que cada pessoa tem uma concepção sobre apoio/ajuda, e atribui diferente importância a cada tipo de apoio, as diferenças nos relatos podem ser enca- 
radas como normais. Outra possibilidade está relacionada com a compreensão do fenômeno em si - as mães podem ter dificuldades para identificar e descrever o apoio recebido e suas diferentes formas, omitindo algumas que são ou foram fornecidas por membros de sua rede social de apoio, não havendo uma visão mais geral do apoio recebido. Por outro lado, a verbalização das fontes de apoio pode estar apoiada na visão do que é socialmente aceito, havendo esforço em citar o maior número possível de situações de ajuda. Por fim, o apoio pode ser oferecido pelas fontes de apoio mesmo quando não é solicitado pelas mães, demonstrando identificação das necessidades das mães e de suas famílias e disposição em ajudar.

A fim de coletar dados mais precisos, outras metodologias poderiam ser empregadas para se comparar o relato das mães sobre o apoio recebido e o das fontes de apoio sobre a ajuda fornecida. Instrumentos que reflitam adequadamente o fenômeno estudado, clarificando os tipos de apoio existentes e como eles podem se configurar e se manifestar, dando inúmeros exemplos e possibilidades de apoio e ajuda, podem ser construídos. Figuras, frases e até mesmo a apresentação de vídeos poderiam ser úteis, principalmente para as mães.

Referente à opinião das fontes de apoio sobre o apoio fornecido, bem como sobre a presença de necessidades, dificuldades e limitações, algumas considerações devem ser feitas. De forma geral, necessidades para ajudar de melhor forma as mães não foram relatadas pelas fontes de apoio. Quando houve esse tipo de relato, a necessidade referia-se à condição financeira da pessoa, o que em sua opinião limitava a ajuda. Nesse sentido, é possível notar a importância dada pelas fontes de apoio à ajuda prática, a qual é fornecida em maior quantidade e variedade. Entretanto, uma possível implicação de focalizar a ajuda nos aspectos materiais é a menor atenção às outras necessidades dessas mães e de suas famílias. Companhia, por exemplo, que poderia ser considerada fundamental para a redução do isolamento social dessas mães, foi o tipo de apoio menos fornecido.

No que se refere às dificuldades e limitações para ajudar as mães, cabe destacar que as próprias fontes podem necessitar de apoio em sua função de apoiadores. A maioria dessas pessoas são membros da família, sendo que tal status por si só pode implicar em maior proximidade e atuação na vida das mães, bem como sentimento de responsabilidade sobre elas e seus filhos. Dependendo da intensidade e frequência da ajuda fornecida, sentimentos como desânimo, cansaço, esgotamento e desvalorização podem surgir, além da conscientização de que deixa de fazer para si para fazer pelo outro. Estes aspectos são vistos claramente no caso de M2 e suas fontes de apoio. Portanto, programas e serviços visando apoiar a mãe com deficiência intelectual devem olhar também para aquelas pessoas mais próximas e atuantes na vida da mãe.

Apesar das dificuldades e limitações apontadas, os resultados do presente estudo demonstraram que em sua maioria, as fontes de apoio gostam de ajudar a mãe e sua família, encaram-no como útil e importante para a mãe e até mesmo para sua própria vida. Preocupação, consideração, carinho, foram aspectos presentes nas falas das fontes de apoio, podendo ser vistos como motivadores para o apoio que fornecem.

Apoio informal fornecido pelas fontes de apoio indicadas pelas mães, presença de um parceiro não abusivo ou violento em alguns casos, benefícios fornecidos pelo governo (Bolsa-Família e cestas básicas, por exemplo), são aspectos positivos presentes na vida das mães participantes do estudo. Apoio informal e presença de parceiros também foram indicados nos estudos realizados por Aunos et al. (2008), Holburn et al. (2001), Willems et al. (2007), como aspectos importantes para essa população. No entanto, a importância dos aspectos citados anteriormente deve ser atribuída com cautela. No caso do fornecimento de benefícios do governo, por exemplo, treinamentos que ensinem as mães a lidar com o que recebem não são oferecidos, favorecendo a exploração por terceiros e usos indevidos e desnecessários dos benefícios (Postalli et al., 2011), o que pode se tornar um fator estressante para a vida das famílias. Apesar da ausência de treinamentos, é interessante observar quantas ajudas financeiras essas mães conseguem para sua família. Algumas questões podem ser levantadas: Quais são os mecanismos existentes que permitem a aquisição dessas ajudas financeiras? Quem as orienta para tal? Estudos futuros que explorem o empoderamento dessas mães, dando atenção para tais questões, deveriam ser realizados.

Embora tenham sido observados casos em que as mães tiveram inúmeras dificuldades para criar e cuidar de seus filhos, também houve casos em que as mães pareceram ser afetuosas e fornecer cuidados e atenção para os mesmos. Diversos fatores podem estar relacionados às diferenças entre essas mães, e como o presente estudo não investigou esses aspectos, não é possível fazer afirmações sobre as inter-relações presentes entre eles, mas nota-se que o apoio social está diretamente envolvido com o exercício da maternidade, como observado em alguns estudos (Aiello \& Buonadio, 2003; Feldman et al., 2002; Tarleton \& Ward, 2007; Traustadóttir \& Sigurjónsdóttir, 2008; Willems et al., 2007). Dessa forma, pesquisadores deveriam explorar que características da rede de apoio dessa população podem estar relacionadas à maneira como essas mães cuidam dos seus filhos e à ocorrência de negligência, abandono e perda da guarda das crianças.

\section{Considerações Finais}

Os resultados obtidos fornecem-nos apenas indícios, que ainda devem ser olhados com cautela. Uma limitação que pode ter contribuído para a variedade dos resultados refere-se ao tamanho da amostra estudada - se o número de participantes fosse maior, os resultados poderiam ser diferentes e até mesmo permitir generalização. A dificuldade de acesso a essas mães contribuiu para esse problema. 
Além disso, os resultados encontrados evidenciam a necessidade de serviços destinados a mães com deficiência intelectual, como observado anteriormente por Aiello e Buonadio (2003). Estas autoras encorajam pesquisadores e profissionais brasileiros a focar sua atenção nas dificuldades enfrentadas por pais com deficiência intelectual e na inexistência de serviços públicos no país, sendo um desafio tornar tais serviços disponíveis para essa população. A existência de serviços, treinamento e atendimentos que ajudem a reduzir o impacto de quaisquer dificuldades que esses pais tenham para criar seus filhos é fundamental (Sheerin, 1998).

Os serviços para esta população devem ser individualizados, visto que cada mãe possui necessidades diferentes; devem ser intensos e constantes no início, e espaçados com o passar do tempo, uma vez que as mães devem se tornar empoderadas para lidar com situações cotidianas sem ajuda profissional; e devem ter uma abordagem sistêmica, intervindo na família como um todo, e se possível na comunidade na qual a família está inserida. Assim, um desafio é encontrar maneiras para que tais mães possam ser assistidas no sentido de desenvolver redes de apoio locais e baseadas na comunidade para ajudar nas demandas da tarefa de se criar um filho.

\section{Referências}

Aiello, A. L. R., \& Buonadio, M. C. (2003). Mães com deficiência mental: O retrato de uma população esquecida. In M. C. Marquezine, M. A. Almeida, S. Omote, \& E. D. O. Tanaka (Eds.), O papel da família junto ao portador de necessidades especiais (pp. 131-146). Londrina, PR: Editora da Universidade Estadual de Londrina.

Associação Brasileira de Empresas de Pesquisas. (2007). Critério Padrão de Classificação Econômica Brasil/2007. Recuperado em http://www.abep.org/novo/FileGenerate.ashx?id=249

Aunos, M., Feldman, M., \& Goupil, G. (2008). Mothering with intellectual disabilities: Relationship between social support, health and well-being, parenting and child behaviour outcomes. Journal of Applied Research in Intellectual Disabilities, 21, 320-330.

Barros, R. D., Williams, L. C. A., \& Brino, R. F. (2008). Habilidades de auto proteção acerca do abuso sexual em mulheres com deficiência mental. Revista Brasileira de Educação Especial, 14(1), 93-110.

Booth, T. (2003). Parents with learning difficulties and the stolen generation. Journal of Learning Disabilities, 7(3), 203-209.

Booth, T., \& Booth, W. (1994). Working with parents with mental retardation: Lessons from research. Journal of Developmental and Physical Disabilities, 6(1), 23-41.

Booth, T., \& Booth, W. (2002). Men in the lives of mothers with intellectual disabilities. Journal of Applied Research in Intellectual Disabilities, 15, 187-199.

Buonadio, M. C. (2003). Análise da interação de mães com deficiência mental e seus filhos: Intervenção domiciliar (Dissertação de mestrado em Educação Especial, Universidade Federal de São Carlos, SP, Brasil).

Cassel, J. C. (1976). The contribution of the social environment to host resistance. American Journal of Epidemiology, 104(2), 107-123.
Dessen, M. A., \& Braz, M. P. (2000). Rede social de apoio durante transições familiares decorrentes do nascimento de filhos. Psicologia: Teoria e Pesquisa, 16(3), 221-231.

Ehlers-Flint, M. L. (2002). Parenting perceptions and social supports of mothers with cognitive disabilities. Sexuality and Disability, 20(1), 29-51.

Feldman, M. A. (1986). Research on parenting by mentally retarded persons. Psychiatric Clinics of North America, 9(4), 777-796.

Feldman, M. A., Varghese, J., Ramsay, J., \& Rajska, D. (2002). Relationships between social support, stress and motherchild interactions in mothers with intellectual disabilities. Journal of Applied Research in Intellectual Disabilities, 15, 314-323.

Gallagher, E. (2001). Parents with an intellectual disability: Common problems. Retrieved February 15, 2007, from http:// home.datacodsl.com/eddiegallagher/Issues\%20for\%20parents\%20with\%20an\%20I.D.pdf

Guinea, S. M. (2001). Parents with a learning disability and their views on support received: A preliminary study. Journal of Learning Disabilities, 5(1), 43-56.

Holburn, S., Perkins, T., \& Vietze, P. (2001). The parent with mental retardation. International Review of Research in Mental Retardation, 24, 171-210.

Kroese, B. S., Hussein, H., Clifford, C., \& Ahmed, N. (2002). Social support networks and psychological well-being of mothers with intellectual disabilities. Journal of Applied Research in Intellectual Disabilities, 15, 324-340.

Llewellyn, G. (1993). Parents with intellectual disability: Facts, fallacies and professional responsibilities. Community Bulletin, 17(1), 10-19.

Llewellyn, G. (1994). Being a parent with intellectual disability: A battle against the odds. Community Bulletin, 18(1), 9-13.

Llewellyn, G. (1995). Relationships and social support: Views of parents with mental retardation/intellectual disability. Mental Retardation, 33, 349-363.

Llewellyn, G., \& McConnell, D. (1998). Parental disability and the threat of child removal. Family Matters, 51, 33-36.

Llewellyn, G., \& McConnell, D. (1999, July). Sharing the care: the Support Interview Guide (A. L. R. Aiello, Trans.). Paper presented at the IIth Australasian Human Development Conference, Sydney, Australia.

Llewellyn, G., \& McConnell, D. (2002). Mothers with learning difficulties and their support networks. Journal of Intellectual Disability Research, 46(1), 17-34.

Llewellyn, G., Traustadóttir, R., McConnell, D., \& Sigurjónsdóttir, H. B. (2010). Parents with intellectual disabilities: Past, present and futures. Chichester, UK: John Wiley \& Sons.

McConnell, D., Dalziel, A., Llewellyn, G., Laidlaw, K., \& Hindmarsh, G. (2009). Strengthening the social relationships of mothers with learning disabilities. British Journal of Learning Disabilities, 37, 66-75.

Postalli, L. M. M., Munuera, R. F., \& Aiello, A. L. R. (2011). Caracterização de família de mãe com deficiência intelectual e os efeitos no desenvolvimento dos filhos. Revista Brasileira de Educação Especial, 17(1), 37-52.

Sheerin, F. (1998). Parents with learning disabilities: A review of the literature. Journal of Advanced Nursing, 28(1), 126-133.

Tarleton, B., \& Ward, L. (2007). "Parenting with support": The views and experiences of parents with intellectual disabilities. Journal of Policy and Practice in Intellectual Disabilities, 4, 194-202. 
Thompson, J. R., Hughes, C., Schalock, R. L., Silverman, W., Tasse, M. J., Bryant, B., ...Campbell, E. M. (2002). Integrating supports in assessment and planning. Mental Retardation, 40, 390-405.

Traustadóttir, R., \& Sigurjónsdóttir, H. B. (2008). The 'mother' behind the mother: Three generations of mothers with intellectual disabilities and their family support networks. Journal of Applied Research in Intellectual Disabilities, 21, 331-340.

Whitman, B. Y., Graves, B., \& Accardo, P. J. (1989). Training in parenting skills for adults with mental retardation. Social Work, 46, 431-434.

Willems, D. L., de Vries, J. N., Isarin, J., \& Reinders, J. S. (2007). Parenting by persons with intellectual disability: An explorative study in the Netherlands. Journal of Intellectual Disability Research, 51(7), 537-544.

Williams, L. C. A. (2003). Sobre deficiência e violência: Reflexões para uma análise de revisão de área. Revista Brasileira de Educação Especial, 9(2), 141-154.

Williams, L. C. A., \& Aiello, A. L. R. (2001). O Inventário Portage Operacionalizado: Intervenção com famílias. São Paulo, SP: Memnon. 